\title{
Dextrocardia and Situs Inversus Totalis in a Turkish Subject: A Case Report
}

\author{
Dextrocardia y Situs Inversus Totalis en un Sujeto Turco: Reporte de un Caso
}

\author{
Seher Yilmaz'; Abdullah Demirtas²; Adem Tokpinar¹ \& Niyazi Acer ${ }^{3}$
}

YILMAZ, S.; DEMIRTAS, A.; TOKPINAR, A. \& ACER, N. Dextrocardia and situs inversus totalis in a turkish subject: a case report. Int. J. Morphol., 37(3):900-902, 2019.

SUMMARY: Dextrocardia with situs inversus is an uncommon anomaly affecting about 1 to 2 per 10,000 in the general population. This report describes an adult male patient with dextrocardia and in a Turkish subject. The photographic illustrations revealed transposition of some of the visceral organs such as the spleen was located right and the liver and gall bladder on the left. The heart was flattened and flipped to the right. Many people with situs inversus totalis are unaware of their unusual anatomy until they seek medical attention for an unrelated condition. So, early detection may lead to a successful surgical management and consequently offer a safer chance of survival. This report showed that dextrocardia and situs inversus can be seen amongst Turkish subjects.

KEY WORDS: Dextrocardia; Situs inversus totalis; Rare anomaly.

\section{INTRODUCTION}

'Situs' means the position of heart i.e. the cardiac atria and viscera. When there is occurrence of mirror image it is termed as 'Situs inversus' i.e. mirror image of as that suppos on the normal position. Dextrocardia is a term used exclusively for defining the positioning of heart i.e. the tip of heart points to the right side. A very few cases of situs inversus totalis has been described in literature i.e. Dextrocardia with Situs inversus (Jasrotia et al., 2016).

Dextrocardia with situs inversus is a condition that is characterized by abnormal positioning of the heart and other internal organs. Situs inversus refers to the mirrorimage reversal of the organs in the chest and abdominal cavity. Some affected people have no obvious signs or symptoms). In people affected by dextrocardia, the tip of the heart points towards the right side of the chest instead of the left side. However a small percentage of people also have congenital heart defects, usually transposition of the great vessels (National Organization for Rare Disorders, 2007; MedlinePlus, 2014; Wilhelm, 2018).

Situs inversus totalis is a very rare autosomal recessive entity (Piryani et al., 2007). normally does not cause any organ dysfunction, few patients with situs inversus totalis have been previously reported in the literatüre. This report showed that dextrocardia and situs inversus can be seen amongst Turkish subjects.

\section{CASE REPORT}

An 87-year-old male patient was admitted to Erciyes University urology clinic with a complaint of blood in the urine. The patient continues to consume 1 pack (20 cigarettes) per day for 40 years. Examination of the cardiovascular system revealed a normal pulse rate of 86 minute and blood pressure was $130 / 80 \mathrm{mmHg}$. Ultrasonography showed a $4 \mathrm{~cm}$ solid mass lesion in the anterior wall of the bladder (Figs. 1 and 2). The patient underwent cystourethroscopy and transurethral resection (TUR-CT) was performed on the bladder tumor. As a result of pathology, high-grade interchangeable epithelial carcinoma and tumor invasion were detected in the bladder muscles. The patient underwent thoracic and abdominal computed tomography (CT) for staging of bladder cancer.

\footnotetext{
${ }^{1}$ Department of Anatomy, Faculty of Medicine, Bozok University, Yozgat, Turkey.

${ }^{2}$ Department of Urology, Faculty of Medicine, Erciyes University, Kayseri, Turkey.

${ }^{3}$ Department of Anatomy, Faculty of Medicine, Erciyes University, Kayseri, Turkey.
} 
CT images revealed. T2N0M0 was defined as clinical stage and radical cystoprostatectomy was performed. The pathological staging was consistent with preoperative clinical staging and the patient was followed up with routine urobiological follow-up.

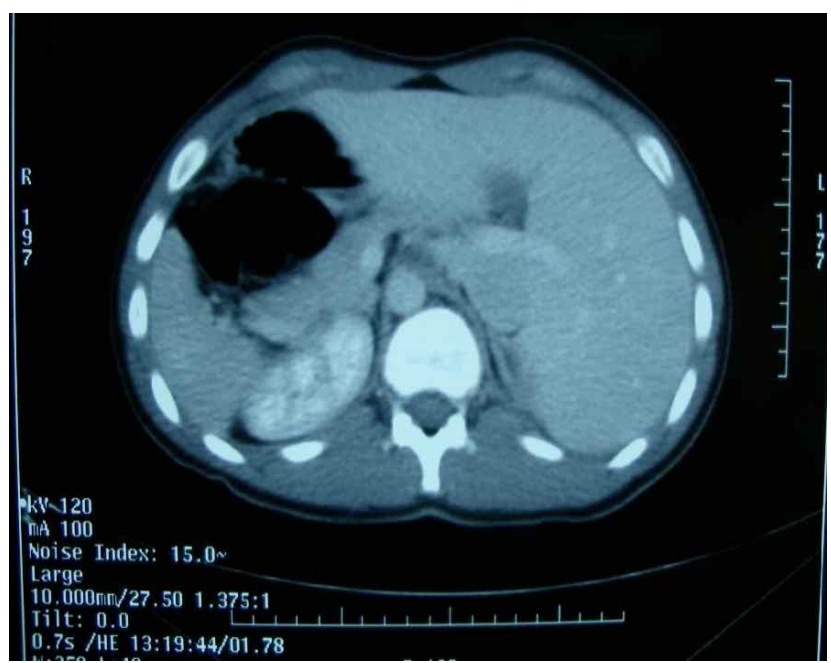

Fig. 1. Computerized tomography image of patient (Heart is on the right side).

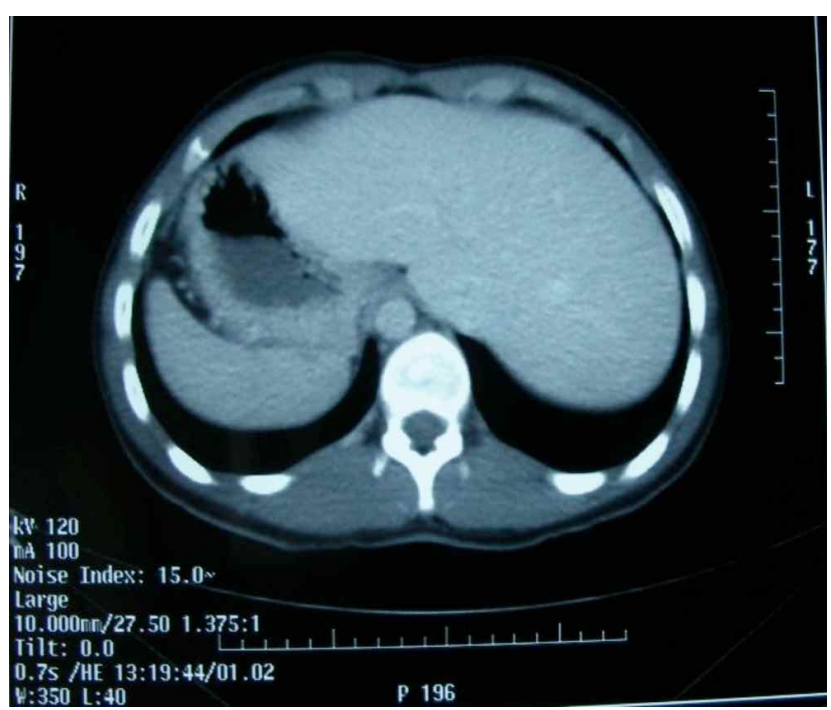

Fig. 2. Computerized tomography image of patient (Liver is on the left side).

\section{DISCUSSION}

Situs inversus totalis was first described by Aristotle in animal and by Fabricius in humans. Situs inversus totalis is defined as a complete mirror-image transposition of the thoracic and abdominal viscera (Piryani et al.). With the increasing use of surgical modalities in the treatment, various clinical manifestations are faced by surgeons, one of which is situs inversus totalis. Dextrocardia with situs inversus is a rare anomaly occurring in about one of 10,000 people. This anomaly may not be diagnosed until later in life, in some cases situs inversus is commonly associated with serious primary ciliary dyskinesis and splenic malformations (Deuse \& Reitz, 2009). Its frequency is between 1 in 8,000 to 1 in 20,000. it may be situs inversus totalis or incomplete in less than $10 \%$ of cases (Chaturvedi \& Thomas, 2003).

Dextrocardia with situs inversus is asymptomatic. Many people with situs inversus totalis are unware of their unusual anatomy until they seek medical attention for an unrelated condition (Chaturvedi \& Thomas).

Situs inversus with dextrocardia also is termed as situs inversus totalis because the cardiac position as well as atrial chambers and abdominal viscera, is a mirror image of normal anatomy (Van Praagh, 1977). There are some case reports on situs inversus totalis with various types of cancers, almost all of the reports describe that the surgical procedures are difficult because of the anatomic abnormality, and there are no reports of the etiological relationship between situs inversus totalis and cancer (Özben et al., 2010). Situs inversus may be associated with other congenital anomalies such as duodenal atresia, asplenism, multiple spleens, ectopic kidney, horseshoe kidney and various pulmonary and vascular abnormalities. Situs inversus totalis that is associated with primary ciliary dyskinesia is known as Kartagener syndrome (Bohun et al., 2007; Ortega et al., 2007).

David A. et al. in their case report found that the stomach and spleen were located on the right side, while the liver was on the left side. The gallbladder was located in the epigastric area toward the left side (Ofusori et al., 2009; Özben et al.).

Typically, persons having situs inversus with dextrocardia without other congenital anomaly have a normal life expectancy and have a similar risk of getting acquired disease as that of other person of same age and sex group. In the rare instances of cardiac anomalies, life expectancy is reduced, depending on the severity of the defect (Bohun et al.).

Detection of bladder cancer in our patient also confirms the increase in the rate of cancer in situs inversus; situs inversus is asymptomatic and does not cause any long term problems, it is very dangerous if the condition is not diagnosed prior to surgery. Situs inversus is present in 0.01 $\%$ of the population of United States (Wilhelm) but its incidence in Turkey is unknown. 
Nawaz H. et al. (2005) in their report described a case of two newborns with situs inversus in association with congenital duodenal obstruction.

Surgeons and radiologists should beware of this anomaly during the presurgical and surgical management and also encourage a routine medical examination which could give a signal to the existence of this condition if present (Ofusori et al.). This will help the patient when afflicted with certain clinical conditions such as appendicitis; where the referred pain will be on the left side rather than the right thus leading to wrong diagnosis and possibly death due to delay in surgical management (Chaturvedi \& Thomas; Ofusori et al.).

\section{CONCLUSION}

The condition is rare and with limited literature. We therefore, in conclusion, sensitize the surgeons and radiologists to beware of this anomaly during the presurgical and surgical management and also encourage a routine medical examination which could give a signal to the existence of this condition if present. Additionally, we believe that the sharing of experience of this rare type of patient is important and will be able to guide future surgical procedures.

Informed consent: Written informed consent was obtained from patieant who participle in this study.

YILMAZ, S.; DEMIRTAS, A.; TOKPINAR, A. \& ACER, N. Dextrocardia y situs inversus totalis en un sujeto turco: reporte de un caso. Int. J. Morphol., 37(3):900-902, 2019.

RESUMEN: La dextrocardia con situs inversus es una anomalía poco frecuente que afecta aproximadamente de 1 a 2 personas por 10.000 en la población general. Este informe describe un paciente masculino adulto con dextrocardia. Las figuras revelaron que la transposición de algunos de los órganos viscerales, como el bazo, se ubicada a la derecha y el hígado y la vesícula biliar a la izquierda. El corazón fue aplastado y girado hacia la derecha. Muchas personas con situs inversus totalis desconocen su anatomía inusual hasta que buscan atención médica por una afección no relacionada. Por lo tanto, la detección temprana puede llevar a un manejo quirúrgico exitoso y, en consecuencia, ofrecer una posibilidad más segura de supervivencia. Este informe mostró que la dextrocardia y el situs inversus se pueden encontrar entre los sujetos turcos.

PALABRAS CLAVE: Dextrocardia; Situs inversus totalis; Anomalía rara.

\section{REFERENCES}

Bohun, C. M.; Potts, J. E.; Casey, B. M. \& Sandor, G. G. A populationbased study of cardiac malformations and outcomes associated with dextrocardia. Am. J. Cardiol., 100(2):305-9, 2007.

Chaturvedi, P. \& Thomas, K. Congenital renal anomaly in a patient with situs inversus. Postgrad. Med. J., 79(932):355-9, 2003.

Deuse, T. \& Reitz, B. A. Heart-lung transplantation in situs inversus totalis. Ann. Thorac. Surg., 88(3):1002-3, 2009.

Jasrotia, R.; Chauhan, G.; Dhanjal, G. S. \& Lohan, R. Dextrocardia and situs inversus totalis in a newborn- A rare case report. Int. J. Curr. Res., 8(2):26934-7, 2016.

MedlinePlus. Dextrocardia. MedlinePlus, 2014. Available from:http:// www.nlm.nih.gov/medlineplus/ency/article/00732.htm

National Organization for Rare Disorders (NORD). Dextrocardia with Situs inversus. National Organization for Rare Disorders (NORD), 2007. Available from: https://rarediseases.org/rare-diseases/dextrocardiawith-situs-inversus

Nawaz, A.; Matta, H.; Hamchou, M.; Jacobez, A.; Trad, O. \& Al Salem, A. H. Situs inversus abdominus in association with congenital duodenal obstruction: a report of two cases and review of the literature. Pediatr. Surg. Int., 21(7):589-92, 2005.

Ofusori, D. A.; Okwuonu, C. U.; Ude, R. A. \& Adesanya, O. A. Dextrocardia and situs inversus totalis in a Nigerian cadaver: a case report of rare anomaly. Int. J. Morphol., 27(3):837-40, 2009.

Ortega, H. A.; Vega, N. de A.; Santos, B. Q. \& Maia, G. T. Primary ciliary dyskinesia: considerations regarding six cases of Kartagener syndrome. J. Bras. Pneumol., 33(5):602-8, 2007.

Özben, V.; Çarkman, S.; Aytaç, E. \& Salihoglu, Z. Laparoscopic cholecystectomy in a patient with situs inversus totalis. Firat Tip Dergisi, 15(1):67-9, 2010.

Piryani, R. M.; Shukla, A.; Prasad, D. N.; Kohli, S. C.; Shrestha, G. \& Singh, D. Situs inversus with dextrocardia with multiple cardiac lesions in adult. Kathmandu Univ. Med. J. (KUMJ), 5(2):247-9, 2007.

Van Praagh, R. Terminology of congenital heart disease. Glossary and commentary. Circulation, 56(2):139-43, 1977.

Wilhelm, A. Situs inversus Imaging. Medscape, 2018. Available from: http:/ /emedicine.medscape.com/article/413679-overview

Corresponding author:

Adem Tokpinar

Department of Anatomy

Faculty of Medicine

Bozok University

Yozgat

TURKEY

Email: ademtokpinar@gmail.com

Received: 12-12-2018

Accepted: 05-02-2019 